\title{
OS CONHECIMENTOS ALTERNATIVOS E CIENTÍFICOS NA ÁREA DE CIÊNCIAS NATURAIS: UMA REVISÃO A PARTIR DA LITERATURA INTERNACIONAL
}

\section{Scientific and alternative knowledge in the field of natural sciences: a review of the international literature}

\author{
Darcy Ribeiro de Castro $^{1}$. Nelson Rui Ribas Bejarano ${ }^{2}$
}

\begin{abstract}
Resumo: Este texto trata dos aspectos teóricos dos conhecimentos alternativos e científicos com crianças em faixa etária entre sete e 11 anos de idade, na área de Ciências Naturais. Deriva de uma dissertação de mestrado que estudou os de conceitos de microrganismos e funções vitais de animais e plantas numa escola cooperativista da cidade de Central, estado da Bahia, em 2009-2010. Neste estudo, organizamos uma síntese das concepções espontâneas e científicas, baseada essencialmente na literatura internacional, para fins de contribuir com a análise de conhecimentos das crianças da referida escola. Os principais aspectos estudados sobre os microrganismos foram a estrutura, tamanho e importância; enquanto, para os animais e plantas, foram consideradas, no estudo, as funções de nutrição, trocas gasosas, respiração e transporte, enfatizando as funções digestórias no ser humano. Discutimos as implicações desse referencial para o planejamento de um ensino para as séries iniciais, destacando o conhecimento biológico da criança.
\end{abstract}

Palavras-chave: Ensino de ciências. Animais. Conhecimento científico. Microrganismo. Séries iniciais.

\begin{abstract}
This text deals with the theoretical aspects of alternative and scientific knowledge with children between seven and 11 years of age, in the area of natural sciences. It derives from a dissertation that studied the concepts of microorganisms and vital functions of animals and plants in a cooperative school in Central town, in 2009-2010. In this study, we organize a synthesis of spontaneous and scientific conceptions, based essentially on international literature for the purpose of contributing to the analysis of children's knowledge of that school in this area. The main aspects studied about microorganisms were their structure, size and importance; While, for the animals and plants the functions of nutrition, gas exchange, respiration and transportation were considered, emphasizing the digestive functions in humans. There is a discussion of the implications of this benchmark work for the planning of teaching to this age range, highlighting the biological knowledge of the child.
\end{abstract}

Keywords: Science teaching. Animals. Scientific knowledge. Microorganisms. Initial series.

\footnotetext{
${ }^{1}$ Universidade do Estado da Bahia, campus XXVI. Rua João Guimarães, s/n, Bairro São Francisco. Xique-Xique, BA, Brasil.47.400-000.dcastro@uneb.br

${ }^{2}$ Universidade Federal da Bahia. Salvador, BA, Brasil.
} 


\section{Introdução}

Consideramos, como referencial para o desenvolvimento do presente artigo, trabalhos internacionais voltados para o estudo dos conhecimentos prévios e/ou conhecimentos escolares (científicos) da criança no âmbito das ciências naturais, como: Kwen (2005), Byrne (2003), Byrne e Sharp (2006), Charrier Melillán, Cañál de Leon e Rodrigo Vega (2006), Driver (1985, 1989), Kerr, Beggs e Murphy (2006), Lawson (1988), Sigurjónsdóttir e Thorvaldsdóttir (2010), Tanner e Allen (2005).

Alguns estudos brasileiros, em menor medida, foram também referenciados neste artigo, a saber: Cunha (1993), Cunha e Justi (2008), Hayashi, Porfirio e Favetta (2011), Kawasaki (2006), Kawasaki e Bizzo (2000), Sforni e Galuch (2006), Zompero (2009).

A partir deste trabalho, objetivamos formular uma melhor compreensão sobre as formas de concepção dos(as) alunos(as) com respeito aos conceitos de microrganismos e funções vitais de animais e plantas, e da descrição que eles fazem para compreendê-los. Assim, tivemos como propósito, o uso de tal referencial para analisarmos o conhecimento da criança das séries iniciais na Cooperativa de Ensino de Central (COOPEC) no período de 2009-2010.

O uso de conhecimento das vivências cotidianas da criança como ponte para a construção do conhecimento científico diante da difícil realidade do ensino de Ciências no Brasil, em que a falta de professores habilitados é um dos problemas principais vinculados ao uso de conceitos científicos na escola pelos alunos. Nas séries iniciais, por exemplo, contamos apenas com cerca de $5 \%$ de pesquisas voltadas para o ensino de biologia, conforme assinala Teixeira (2009), num estudo desenvolvido sobre dissertações e teses na área do ensino de Ciências Biológicas no Brasil, no período de 1972 a 2004.

Com base neste autor, percebemos que essas duas questões merecem uma atenção especial porque o baixo percentual de pesquisa sobre a referida área de conhecimento pode limitar o acesso dos professores a tal tipo de formação, até mesmo os já licenciados. Assim, além da falta de professores com formação em biologia, temos aqueles que, embora habilitados na área, não estão capacitados para levar, aos estudantes, um ensino baseado nos seus conhecimentos espontâneos, como meio para elaboração do saber científico.

O estudo da temática envolvendo conceitos de microrganismos e funções vitais de animais e plantas para tal etapa de ensino pode apresentar, em especial, uma possível contribuição para ampliar as pesquisas e o ensino de biologia nas primeiras séries do Ensino Fundamental. A presente revisão de literatura acerca da estrutura e das funções vitais de microrganismos, animais e plantas foi realizada com o objetivo de analisar os conhecimentos espontâneos e científicos (escolares) dos alunos do Ensino Fundamental I da COOPEC. Destacamos os aspectos conceituais de tamanho, hábitat e importância em relação aos microrganismos; consideramos as funções vitais de nutrição, trocas gasosas, transporte, para os animais e plantas, enfatizando as funções digestórias no ser humano.

Com base em Sforni e Galuch (2006), entendemos que, sem conhecimento de conceitos científicos correlatos aos espontâneos, tais conteúdos perdem o seu valor de ação consciente e de prática concreta diante da realidade. Por outro lado, o saber científico, geralmente transmitido na escola como apenas "receita" pronta, não favorece a formação dos conceitos científicos pelos alunos, nem tampouco os fortalece na direção do enfrentamento de problemas do cotidiano. Nessa correlação, desenvolvem-se, reciprocamente, as formas de pensa- 
Os conhecimentos alternativos e científicos ...

mento concreto e abstrato, que caracterizam os conhecimentos espontâneos e científicos, respectivamente.

\section{Os conceitos concretos e abstratos}

De acordo com Kerr, Beggs e Murphy (2006), os conceitos concretos são decorrentes do pensamento perceptual do ser humano, tanto em criança quanto em adulto, enquanto os conceitos abstratos estão relacionados ao modo de pensar dos adultos. Este autor afirma que as crianças ficam no plano da percepção (pensamento concreto), ao descrever sobre as funções vitais dos seres vivos. Podemos estender tal ponto de vista também para a percepção dos aspectos de estrutura/função dos microrganismos, conforme os estudos de Byrne (2003), e de Byrne e Sharp (2006). Isso ocorre porque estes conceitos exigem maior abstração da criança.

Os alunos têm familiaridade com uma série de conceitos científicos, mas o aprofundamento deles, a conexão com pensamentos mais amplos e princípios científicos, é extremamente limitado. Há uma lacuna muito grande entre o conhecimento científico e os conhecimentos espontâneos dos alunos, incluindo as suas concepções alternativas. Esse problema reside na diferença entre o conhecimento dos conteúdos e a sua compreensão correspondente via abstração: o conhecimento está associado à percepção dos fatos, memorização e superficialidade do pensamento; a compreensão tem significado complexo e integrações múltiplas dentro de um referencial de aprendizagem (TANNER; ALLEN, 2005).

\section{As Concepções Alternativas (ACs) sobre funções vitais de seres vivos}

Kwen (2005) estudou muitos equívocos de conceitos de ciências biológicas em relação a plantas, animais, funções vitais de seres vivos na escola primária de Singapura. A investigação deste autor envolveu os níveis de ensino (P3 a P6), que são equivalentes ao Ensino Fundamental I ( $2^{\circ}$ ao $5^{\circ}$ ano), vigente no Brasil. Para tal, foi considerado um conjunto de itens de avaliação, tais como: respiração, circulação e trocas gasosas com o meio ambiente.

Os alunos do nível P3 ( $2^{\circ}$ ano) se referem ao conceito de ser vivo em função da sobrevivência e de forma não sistemática; os alunos do nível P4 ( $3^{\circ}$ ano) evidenciam mecanismos básicos nas suas respostas sobre sistemas que envolvem plantas, animais e seres humanos; inter-relacionam respiração, circulação com trocas gasosas com o meio ambiente, mas misturam os processos de trocas gasosas com os processos de respiração celular no organismo humano. Os alunos do nível P5 ( $4^{\circ}$ ano) iniciam a relação de causa e efeito em relação aos conteúdos citados (KWEN, 2005).

Dentro do programa de ciência de Singapura, os assuntos da respiração externa (extracelular) e respiração interna (celular) são introduzidos progressivamente, a partir do nível (P3) até (P6) na escola primária. Em P3, são introduzidos os conteúdos, como a necessidade básica da água, comida e ar para todas as coisas vivas; os alunos aprendem as diversas partes das plantas e suas funções básicas, mas ainda não conseguem elaborar uma compreensão da relação entre as trocas gasosas externas e a respiração interna. Os sistemas respiratórios e circulatórios de plantas e animais são introduzidos em P4 e os alunos aprendem os diferentes mecanismos utilizados pelas plantas, animais e peixes para trocar gases com o ambiente. Nos 
níveis $\mathrm{P} 5 / \mathrm{P} 6$, os alunos aprendem que a água, a energia da luz e dióxido de carbono são necessários para a fotossíntese e para a produção de açúcar e oxigênio. Eles passam a conhecer também que os alimentos produzidos pelas plantas tornam-se fonte de energia para os animais, e que a respiração é um mecanismo pelo qual a energia é disponibilizada para o desenvolvimento das funções vitais de seres vivos (KWEN, 2005).

Quanto ao funcionamento de sistemas orgânicos humanos, os assuntos fragmentados nos quatro níveis de ensino mantêm uma relação com a dificuldade de compreensão sistêmica dos mesmos, mas considerando os avanços em aprofundamento ao logo das séries escolares. Embora haja aprofundamento nos aspectos de ensino referente ao sistema respiratório em $\mathrm{P} 5 / \mathrm{P} 6$, como, por exemplo, o aluno não compreende que estas estruturas trabalham ao mesmo tempo e de forma interativa.

O estudo sobre o conhecimento das crianças acerca do transporte de substâncias no corpo humano e metabolismo celular indica uma forma de se avaliar a compreensão delas acerca das funções integradas no corpo humano. Segundo a pesquisa 'Children's ideas about living things' (1992), uma criança de seis anos, por exemplo, não entende que o sangue do corpo passa pelos pulmões e retorna ao coração. Entre os sete e nove anos, as crianças ampliam a compreensão do funcionamento do organismo em relação ao conhecimento geral das crianças menores. No final da escola primária, as funções dos órgãos aparecem como explicação causal (cadeia de relação). Desse modo, o conhecimento das funções biológicas no nível que se aproxima dos conceitos científicos a elas correspondentes, mesmo nas crianças mais velhas, depende da abstração dos conteúdos ensinados na escola (CHILDREN'S..., 1992).

\section{Fotossíntese}

Muitos trabalhos (CANAL, 1999; LAWSON, 1988; SIMPSON; ARNOLD, 1982a, 1982b; STAVY; WAX, 1989; WOOD-ROBINSON, 1991) foram desenvolvidos sobre concepções alternativas acerca dos aspectos conceituais gerais da ciência da vida: vida, animais e plantas, corpo humano, reprodução, genética e evolução (décadas de 1980 e 1990). Nestas décadas, as pesquisas também incluíram os aspectos conceituais específicos da vida (respiração, fotossíntese e replicação do material genético). Contudo, estas concepções, para a maioria dos tópicos de biologia, permanecem ainda pouco compreendidas, sobretudo quando se trata do ensino de biologia para as crianças (década de 2000), conforme asseguram Tanner e Allen (2005).

Sigurjónsdóttir e Thorvaldsdóttir (2010), numa pesquisa com crianças irlandesas com idade de dez e 14 /15 anos, concluíram que a compreensão delas sobre fotossíntese é muito pobre e que os objetivos implícitos no currículo estão longe de ser alcançados. Os dois grupos estudados não apresentaram diferenças significativas de entendimento sobre a fotossíntese, por isto, os utilizamos para analisar o conhecimento dos alunos da COOPEC (idade entre 7/ 11 anos).

Este estudo envolveu: os componentes da fotossíntese, seus produtos, a interferência dos fatores como luz, água, gás carbônico, organismos fotossintetizantes, partes dos organismos que realizam a fotossíntese, trocas gasosas e crescimento das plantas. O equívoco de que a fotossíntese é um processo em que o gás carbônico entra no corpo da planta para ocupar o lugar do oxigênio, e que as plantas liberam o oxigênio, é comum entre crianças de dez anos e, também, de 14/15 anos de idade. Esses conhecimentos prevalecem na criança até 14/15 anos 
de idade e, também, em adultos escolarizados e não escolarizados (SIGURJÓNSDÓTTIR; THORVALDSDÓTTIR, 2010).

O conceito básico de fotossíntese está presente em diversas áreas da biologia (biologia celular, fisiologia das plantas, ecologia e botânica), mas, para avançar no seu entendimento conceitual, não se prescinde de conhecimentos elementares em física e química. Se estes conhecimentos forem ensinados aos alunos, espera-se que, a partir dos dez anos de idade, eles saibam explicar quais os componentes que são essenciais para a realização da fotossíntese; quais os produtos da fotossíntese e qual o papel da fotossíntese para o funcionamento dos ecossistemas. Mas, na prática, estes assuntos ainda não são compreendidos, conforme assinalam os estudos de Sigurjónsdóttir e Thorvaldsdóttir (2010).

A maioria dos alunos relaciona a fotossíntese apenas como trocas gasosas, e não como um processo como um todo: apenas $20 \%$ das crianças de dez anos e $40 \%$ das crianças entre 14/15 anos relacionam a matéria orgânica produzida, a partir da matéria inorgânica, com a interferência da energia solar. Mesmo em crianças mais velhas, não houve a relação de que as plantas precisam se nutrir, a partir da energia da luz, e que tal processo se relaciona com a respiração destes seres vivos (SIGURJÓNSDÓTTIR; THORVALDSDÓTTIR, 2010).

Neste sentido, no que tange à fotossíntese, Popov (1995), numa questão que solicitava que os estudantes da escola primária de Moçambique assinalassem as palavras entre parênteses, em relação ao item 'com a ajuda da luz as plantas verdes fabricam (oxigênio/gás carbônico) e matéria (inorgânica/orgânica)', apenas um quinto dos alunos a respondeu corretamente. Os alunos recordam-se melhor de que as plantas verdes produzem oxigênio e têm mais dúvidas acerca da produção da matéria orgânica. Esta é uma questão que exige o uso do pensamento abstrato que ainda está em formação nas crianças dos grupos estudados.

Autores como Hayashi, Porfirio e Favetta (2011), Kawasaki (1998), Kawasaki e Bizzo (2000) têm enfatizado os equívocos e a dificuldade de compreensão de crianças e adolescentes em relação aos aspectos sistêmicos da nutrição vegetal, envolvendo desde conceitos como trocas gasosas, fotossíntese, respiração, alimentação, crescimento até o funcionamento dos ecossistemas. Isso evidencia uma necessidade de mais conhecimento dos professores na área dos conhecimentos espontâneos e alternativos dos alunos (equívocos). É um desafio para a escola ampliar estas formas de pensamento dos alunos através destes conhecimentos.

\section{Microrganismos}

Byrne e Sharp (2006), num estudo sobre microrganismos com crianças de 7, 11 e 14 anos de idade em escolas da Inglaterra, mostraram que todos os alunos envolvidos na pesquisa concebem os microrganismos apenas como seres que não trazem benefícios para a humanidade, e que a maioria das atividades de ensino não trazem êxito para a mudança de pensamento dos alunos. Os microrganismos são concebidos apenas como causadores de doenças.

Neste sentido, os trabalhos de Cunha (1993) e Zompero (2009) acrescentam que as crianças mostram-se confusas, ou ainda não capazes de relacionar os aspectos epidemiológicos básicos acerca das doenças causadas por microrganismos, ou seja, a relação entre causa, transmissão e sintomas de tais enfermidades.

Os aspectos conceituais envolvidos nos estudos de Byrne e Sharp (2006) sobre microrganismos foram os seguintes: origem e estrutura, tamanho, hábitat e função. As respostas 
corretas para estes itens foram aumentando com a idade das crianças. Isso pode ser atribuído ao tempo maior em que as crianças mais velhas tiveram na escola e o contato com outros contextos que contribuem para a aprendizagem, como: a televisão, revistas, anúncios, cartões etc. Embora as crianças maiores já diferenciem os aspectos de células individualizadas e múltiplas células, elas ainda não avançam na descrição da estrutura celular e funcionalidade no sentido de aproximação com a descrição científica dos livros de ciências. Driver (1989) reitera esta questão ao considerar que as contraditórias e negativas ideias ainda são comuns nos alunos mais velhos, quando submetidos a vários contextos e escolaridade.

O uso de microrganismos para a produção de alimentos parece ser pobremente entendido pela maioria das crianças, especialmente, as mais jovens, que se mostram surpresas, e, mesmo horrorizadas, ao serem informadas de que bactérias são usadas para fazer iogurtes. $\mathrm{O}$ uso de microrganismo para tratamento de esgoto não foi reconhecido por alguns alunos e a maioria os considerou como organismos 'fedorentos' e perigosos, que trazem doenças em todos os lugares e devem ser evitados a todo custo. Não foi também reconhecido o uso de microrganismo para produção de vacinas e antibióticos, no sentido de luta contra as infecções (BYRNE, 2003).

Fica evidente a necessidade de se estender a abordagem de conhecimentos dos alunos para além do caráter pejorativo com que eles concebem os microrganismos, através de outras atividades (fabricação de remédios, vacinas, iogurtes etc.). Embora, mesmo avançando na direção dos 14 anos de idade, e com uso das referidas atividades, nesse grupo, as ideias ainda permaneceram contraditórias, fragmentadas, e isso se remete à maneira como tais conteúdos são trabalhados na escola (BYRNE, 2003).

Byrne e Sharp (2006) afirmam que muitas crianças reconhecem os microrganismos como seres vivos, e o movimento é a principal característica que confere essa vitalidade destes seres tão pequenos. O movimento é mais associado a animais do que a plantas, o que leva as crianças a pensarem nos microrganismos como seres vivos que fazem parte do Reino Animal. As maneiras de pensamento das crianças envolvem: movimento, forma, uso para alimentação e morte, sensibilidade às mudanças do meio, como aspecto mais elevado do pensamento imbricado com o surgimento da vida. A concepção de microrganismos como seres minúsculos parece ser bem estabelecida entre as crianças. Entretanto, caracterizar organismos pequenos em nível estrutural e funcional é muito difícil. A descrição que alunos fazem deles se limita à reprodução de imagens externas e pouco entendimento das estruturas internas em relação a saúde, alimentação e meio ambiente.

As crianças, geralmente, afirmam que reconhecem que microrganismos são muito pequenos. Elas apenas têm noção dos microrganismos como alguma coisa que existe, mas ainda invisível a olho nu, e, particularmente, difícil de agarrar. As crianças de sete anos sugerem que os microrganismos são 'finos', 'invisíveis' ou 'muito pequenos', e que não podem ser vistos em pequenos espaços. Outras definições envolvem pedaços de cotão (pelos que se desprendem do tecido de algodão); ideias antropomórficas, e atribuem a virulência ao tamanho dos minúsculos seres. Essas crianças aprendem mais estes conceitos em casa e na família. Dos 11 anos de idade em diante, a maioria das crianças referencia os microrganismos como seres microscópicos, reais e pequenos, e que são capazes de se reproduzirem. Essas crianças usam CD, TV, computador, internet para obtenção de tais conhecimentos, mas estes recursos têm muito pouco impacto no crescimento conceitual destas crianças (BYRNE; SHARP, 2006). 
Muitos dos saberes das crianças sobre estrutura de microrganismos foram enraizados em suas imaginações e fantasias, em vez da informação factual. Em termos de tamanho, muitas crianças têm pouco ou nenhum conceito de seres microscópicos, a não ser a partir da intuição ou experiências diárias. Por isso, vale a pena os professores conhecerem os saberes das crianças e usá-los como ponto de partida para elaboração de formas de pensamentos mais próximas do caráter científico. Para tanto, é necessária a realização de atividades tais como: estação de tratamento de esgoto; explorar diferentes contextos, incluindo anúncios, modelos de estrutura e função; comparação de estruturas microscópicas com objetos, esquemas relacionando ciclo de nutrientes, o papel dos microrganismos e a importância deles para o desenvolvimento da vida na Terra (BYRNE; SHARP, 2006).

Embora os microrganismos habitem diferentes espaços, muitos alunos os associam ao corpo humano, ou a doenças e lugares não higiênicos. Essa associação aumenta com a idade. Por isso, essa falta de abordagem destes conteúdos na escola precisa ser revista, incluindo mais recursos para a educação, no sentido de disponibilizar, para o professor, mais literatura voltada para as crianças (BYRNE; SHARP, 2006).

\section{Tendências do conhecimento biológico}

Lawson (1988), num estudo com crianças do Ensino Fundamental, com idades diferentes, mas com famílias e ambientes comuns, investigou os conhecimentos ingênuos (equívocos) sobre importantes temas de biologia, com o propósito de analisar as tendências do conhecimento biológico. Para isto, ele interroga se a aquisição de conhecimentos biológicos segue um padrão de construção da teoria ingênua/ espontânea e conflito cognitivo, ou se segue um padrão de acumulação gradual de tábula rasa. Pouca evidência se encontra no campo da biologia sobre a primeira situação, mantendo-se dominante a segunda.

A convencional instrução escolar não vem dando conta de contribuir para a minimização dos equívocos conceituais ${ }^{3}$. Há muito a ser dito sobre esse ponto de vista do processo educativo, no sentido de oferecer meios para contribuir para o avanço das ideias alternativas dos alunos. Identificar temas importantes em aulas de ciência, identificar as concepções erradas, modelos de projeto de ensino e aulas específicas poderão ser fortes aliados para minimizar os equívocos, a fim de implantar concepções cientificamente válidas em seu lugar (LAWSON, 1988).

Há pouco êxito nos trabalhos sobre as concepções alternativo-espontâneas dos alunos no tocante às ciências biológicas, sobretudo, no ensino voltado para crianças. Lawson (1988) assegura que, nesta área, os conhecimentos biológicos espontâneos são altamente enraizados, complexos, e parece não encontrar um núcleo comum (elo) entre a experiência pes-

\footnotetext{
${ }^{3}$ Equívocos são definidos como conhecimentos derivados da experiência pessoal extensiva, que é incompatível com a estabelecida teoria científica (LAWSON, 1988 apud HALLOUN; HESTENES, 1985a, p. 1043; 1985b, p. 1056), que podem oferecer resistentes à aquisição cientificamente dos conceitos válidos a partir da instrução escolar.
} 
soal e as visões cientificamente errôneas, a exemplo da dificuldade de distinção entre os conceitos de seres vivos e não vivos. O cerne desta discussão é averiguar se conhecimentos alternativo-espontâneos da criança, para as temáticas supracitadas, podem interferir no ensino nas séries posteriores ao Ensino Fundamental.

Lawson (1988) realizou estudos com crianças com idade de seis anos (Betsy), nove anos (Bob) e dez anos (Matt), numa escola suburbana norte-americana de classe média. Ele concluiu que aspectos específicos de seres vivos, tais como respiração, circulação, digestão e crescimento, não são uniformes, como mostram os tópicos a seguir.

\section{Crescimento de animais e plantas. Como os organismos crescem?}

Os conhecimentos de Betsy e Bob indicam a crença de que o crescimento depende de uma fonte de alimento, ou seja, alimentos para animais e água para as plantas; Betsy: como é que uma planta fica maior? Água. Bob: Como as plantas ficam maiores? A água que eles absorvem (LAWSON, 1988, p. 189). Esta parece ser considerada uma teoria ingênua, um equívoco derivado da observação de que as plantas necessitam de água, como fonte de alimento, para o crescimento. Só Matt tem alguma ideia de como de animais e plantas crescem, a partir das divisões celulares. Este saber não foi derivado de observações diretas dos alunos, e sim da transmissão dos conteúdos feita pelo professor (conhecimento declarativo dogmático).

\section{Fotossíntese. Como as plantas conseguem energia?}

Betsy relaciona água, terra e ar como 'necessário' para o crescimento das plantas. Ela também acredita que a luz desempenha um papel. "Ela brilha na água e faz a planta crescer." (LAWSON, 1988, p.188). Veja a mudança feita por Bob. Ele também acredita que a água é necessária, mas em resposta à pergunta "Como as plantas obtêm seus alimentos?", ele responde: "elas fazem o alimento pela água." (LAWSON, 1988, p. 188). Isto implica uma consciência de que as plantas 'fazem' o alimento e não uma crença de que a água é o alimento. Ainda a ideia de fabricar o alimento não é firme: "eles absorvem a água em suas raízes, e, quando sentem fome, eles levam um pouco da água fora das raízes para absorver a comida" (LAWSON, 1988, p. 188). Bob usou a palavra 'fome', mas murmurou, como se ele estivesse, pelo menos, parcialmente consciente de uma contradição (ela bebe água, não é porque ela está com fome, mas porque ela sente sede, portanto, não faz muito sentido que as plantas absorvem água para aliviar fome).

Matt parece 'saber' que as plantas produzem seus próprios alimentos, e ele pode relacionar ingredientes necessários (ou seja, água, dióxido de carbono, material 'no solo' e luz solar), mas suas aulas não o ajudaram muito na identificação do papel da luz solar neste processo. Observamos que Matt não adquiriu este conhecimento nas experiências escolares, mediante investigação realizada pelos professores sobre o papel da luz no crescimento das plantas.

Lawson (1982) define este tipo de conhecimento como declarativo dogmático, uma vez que não é baseado em experiência, mas representa, simplesmente, a repetição de demonstrações feita por figuras de autoridade do professor. Neste caso, Lawson (1988) argumenta que o uso constante de conhecimentos dogmáticos declarativos não pode fazer nada para ensinar aos alunos sobre os processos de raciocínio compartilhados pela comunidade científica. Além disso, essa abordagem de conhecimento pode entorpecer o espírito de investigação, como ilustram os exemplos: "Você tem realizado algumas experiências com plantas em luz ou escu- 
ridão?" "Não". "Acha engraçado ler sobre esse material?" "Não". Assim, as respostas das crianças não favorecem a superação dos equívocos adquiridos por meio da experiência pessoal.

Experimentos citados por Lawson (1988) comprovaram que nem a água, o solo ou ar são, isoladamente, suficientes para o crescimento das plantas, mas não refutam a hipótese de a água ser usada como fonte de alimento. Popov (1995), numa pesquisa com alunos da escola primária de Moçambique, afirma que $31 \%$ dos alunos concebem que água é o principal alimento que as plantas recebem do solo; $15 \%$ dos alunos mencionaram apenas diferentes componentes do solo, como: areia, húmus, ar, argila etc.; e apenas 3\% dos alunos se recordaram dos sais minerais como nutrientes para as plantas. Popov (1995) identificou que a maioria dos alunos acredita que são os diferentes organismos vivos (ou plantas, ou ervas, ou animais mortos etc.) que fazem as plantas crescerem melhor.

Charrier Melillán, Cañál de Leon e Rodrigo Vega (2006), num trabalho sobre concepções alternativas de nutrição de plantas, afirmaram que as definições dadas pelos alunos acerca de respiração e fotossíntese são similares e têm pouca relação com os conceitos escolares. Nesse sentido, entendemos que "muito antes de ser apresentado à definição escolar de fotossíntese, o aluno traz para dentro da escola idéias a respeito de nutrição, alimento, energia e respiração, mesmo que estas estejam restritas a seus significados cotidianos" (KAWASAKI; BIZZO, 2000, p. 25).

Esses pontos de vista negam as afirmações de Lawson (1988) que dizem respeito à ausência de conhecimentos espontâneos na criança, para estas temáticas.

\section{Sistema respiratório animal.}

\section{Como os animais fazem as trocas gasosas com o meio ambiente?}

Nenhuma evidência de teorias ingênuas existe, e não há evidência de desejo, por parte das crianças, para gerá-las. Parece existir simplesmente uma falta de conhecimento que, mais uma vez, é gradualmente diminuído com fatos dogmáticos obtidos através da leitura ou de ouvir as figuras de autoridade (Betsy: "Você sabe aonde vai o ar quando você o respira na sua boca e nariz?"). "Não". "Tem alguma idéia?" "Não". Bob: "Vai a seu corpo, por algum motivo ou outro, não sei por quê". Matt: "Como você sabe que para conseguir respirar oxigênio? Eu li sobre isso" (LAWSON, 1988, p. 192).

$\mathrm{O}$ aspecto mais marcante dos conhecimentos espontâneos da criança é a falta de generalização conceitual e a resistência deles a quaisquer ideias particulares ou conjunto de ideias autogeradas. A única verdadeira indicação da construção da teoria espontânea e ingênua sobre o tema da fotossíntese é apresentada quando crianças (Betsy e Bob) afirmam que água é uma fonte primária de alimentos para os vegetais (LAWSON, 1988). Isto é um contraste em relação às ciências físicas em que as crianças têm evidenciado substanciais teorias ingênuas para os fenômenos naturais. Mas, nos últimos vinte anos, têm aumentado as pesquisas acerca dos conhecimentos espontâneos das crianças na área de biologia (um aumento aproximado de cem para novecentos trabalhos), conforme assinalam Tanner e Allen (2005).

\section{A digestão dos animais. Como os animais digerem os alimentos?}

Há um claro aumento no conhecimento da digestão com a idade e da visão de processo/interação sistêmica em relação ao transporte de nutrientes pelo sangue e a nutrição do organismo. Notamos que Betsy inventou uma teoria ingênua sobre os alimentos. Isto aconte- 
ce quando ela afirma que o alimento vai para o pé, mas não para o cérebro. É evidente, porém, assinalar que esta teoria não é bem articulada e fácil, portanto, de ser descartada, como ilustra o exemplo anteriormente apresentado: "se eu lhe dissesse que alimentos foram para o cérebro, você acredita em mim?" "Sim". Assim, sua teoria ingênua não se qualifica como um equívoco 'profundamente enraizado', na medida em que parece não resistente à instrução, nem articulada com outros conceitos (LAWSON, 1988).

\section{Digestão e nutrição em seres humanos}

Os estudos mostram que, a partir do dez anos de idade, as crianças são capazes de compreender que o corpo humano é composto por numerosos órgãos que funcionam juntos para manter o organismo vivo. Uma criança com esta idade conhece alguns dos mecanismos pelos quais os atos de comer e respirar ajudam o funcionamento do corpo humano. Esse conhecimento ainda não é perfeito, pois tais mecanismos só poderão ser melhores desenvolvidos na adolescência, consoante o ensino na escola, mais precisamente no ensino secundário. Uma criança de dez anos não compreende que os alimentos são quebrados em nutrientes através do processo de digestão (CHILDREN'S..., 1992).

Cunha e Justi (2008), num estudo sobre digestão e nutrição com crianças do Ensino Fundamental I, afirmam que, apesar de os estudantes deste nível de ensino possuírem conceitos científicos sobre o tema, os conceitos adquiridos por eles na vida cotidiana influenciam muito a descrição (desenhos e analogias) que fazem sobre as estruturas do sistema digestório e a dinâmica da digestão dos alimentos.

As crianças usaram termos científicos como esôfago, intestino e estômago. Entretanto, na maioria das vezes, elas não conseguiam explicar de maneira satisfatória a função ou anatomia dessas estruturas. Seus saberes são bastante fundados em conhecimentos adquiridos com a experiência cotidiana e, também, a partir da educação recebida por seus pais ou pela mídia. Um exemplo disto é a crença que elas têm de que 'comidas boas', aquelas que nos dão energia para as nossas atividades, são as frutas, legumes, arroz e feijão, enquanto guloseimas, como chocolate e balas, não fornecem subsídio para realizarmos atividades físicas ou nos mantermos vivos.

Outro aspecto relevante do estudo de Cunha e Justi (2008) é o de que nenhuma das crianças entrevistadas apresentou uma noção de transformação química dos alimentos. Isto, como foi também concluído por Teixeira (2000), é necessário para que se estabeleçam relações entre os vários sistemas que compõem o corpo humano. É evidente que as crianças não estabelecem essas relações prontamente. Esse fato pode prejudicar a aprendizagem de outros conteúdos ou reforçar algumas ideias incoerentes com os conceitos científicos.

Segundo Popov (1995), numa pesquisa com alunos da escola primária de Moçambique, $57 \%$ dos alunos reconheceram corretamente as diferentes funções do corpo humano de acordo com os seus nomes científicos. Os maiores de índices de acertos dos alunos foram para as funções respiratória $(80 \%)$, digestória $(79 \%)$, circulatória $(72 \%)$ e excretora $(68 \%)$. Esse bons resultados podem ser explicados pelas seguintes razões: aulas recentes sobre o assunto e tarefas extraclasses recomendadas pelos manuais didáticos, que contribuem para a memorização dos conteúdos. Estas pesquisas reforçam o predomínio da transmissão do conhecimento escolar de forma unidirecional e fragmentada. 
De acordo a pesquisa 'Children's ideas about living things' (1992), muitas crianças não distinguem entre as propriedades do corpo humano e suas partes constituintes. Elas compreendem apenas as funções estáticas dos órgãos: o coração é para amar; o cérebro é para pensar. A coerência funcional, em nível sistêmico, começa ser evidenciada nos 08 (oito) ou 09 (nove) anos de idade, mas de forma associada aos movimentos de substâncias no organismo, tais como: alimentos, ar e sangue. Neste sentido, os órgãos são reservatórios que são comunicados por canais ou vasos sanguíneos (CHILDREN'S..., 1992).

\section{Considerações finais}

De uma forma geral, podemos afirmar que, embora exista uma base comum referente às concepções alternativas dos alunos sobre os microrganismos, animais e plantas em diferentes países, como asseguram Byrne e Sharp (2006) e Driver (1985), percebemos que as discordâncias são bastante visíveis em relação a essas temáticas.

Por essa razão, no presente trabalho, destacamos duas abordagens consensuais e gerais em que se consideram: 1) um bom número de conhecimentos alternativos nas crianças que fizeram parte da pesquisa; 2) pouco conhecimento alternativo/espontâneo acerca dos seres vivos.

Os conceitos biológicos espontâneos/alternativos e científicos apresentados acerca de microrganismos (BYRNE; SHARP, 2006), vegetais (KWEN, 2005; CHARRIER MELILLÁN; CAÑÁL DE LEON; RODRIGO VEGA, 2006; CHILDREN'S..., 1992; KAWASAKI; BIZZO, 2000) e animais (CUNHA; JUSTI, 2008; TEIXEIRA, 2000) indicaram, sobremaneira, um ponto de partida para a aquisição dos conceitos científicos correspondentes para as crianças. Por outro lado, autores como Lawson (1988), Popov (1995), Sigurjónsdóttir e Thorvaldsdóttir (2010), ao afirmarem que há poucos conhecimentos espontâneos/alternativos acerca das funções vitais supracitadas, reiteram que isto em quase nada contribui para o ensino dessas temáticas na escola.

$\mathrm{Na}$ COOPEC, utilizamos a primeira abordagem para analisar os conteúdos e processos envolvidos na compreensão dos conceitos de microrganismos, plantas e animais pelos alunos das séries iniciais. Em menor medida, percebemos a limitação de conhecimento dos alunos, sobretudo quando os conteúdos não foram desenvolvidos em sala de aula ou não são comuns ao seu cotidiano (tamanho de microrganismo e interação entre sistemas orgânicos de animais e plantas). Isso foi uma alternativa fundamental para o planejamento das atividades de ensino na referida escola, a partir de 2009, com vistas à ampliação e análise dos conhecimentos espontâneos/alternativos e escolares das crianças.

Notamos, enfim, que a base comum das concepções prévias dos alunos ora relatada neste texto está aliada a uma visão interativa das crianças acerca dos microrganismos, plantas e animais. Os conhecimentos alternativos/espontâneos sobre estrutura/tamanho de microrganismos e funções vitais de animais e plantas são saberes abstratos que demandam tempo para as crianças se apropriarem deles no plano concreto. Por isso, apresentar conhecimento cientificamente coerente sobre esses conteúdos é importante para que os alunos consigam ter uma visão global e mais factual do funcionamento do organismo, considerando a interdependência das funções de cada sistema. 
Castro, D. R.; Bejarano, N. R. R.

\section{Referências}

BYRNE, J. Progression of children's ideas and understanding about microbial activity. In: CONFERENCE OF THE EUROPEAN SCIENCE EDUCATION RESEARCH ASSOCIATION, 4., 2003, Noordwijkerhout. Proceedings... Utrecht: ESERA, 2003.

BYRNE, J.; SHARP, J. Children's ideas about micro-organisms. School Science Review, London, v. 88, n. 322, p. 71-79, 2006.

CANAL, P. Photosynthesis and 'inverse respiration' in plants: an inevitable misconception? International Journal of Science Education, London, v. 21, n. 4, p. 363-372, 1999.

CHARRIER MELILLÁN, M.; CAÑÁL DE LEON, P.; RODRIGO VEGA, M. Las concepciones de los estudiantes sobre la fotosintesis y la respiracion: una revisión sobre la investigación didáctica en el campo de la enseñanza y el aprendizaje de la nutrición de las plantas. Enseñanza de las Ciencias, Barcelona, v. 24, n. 3, p. 401-410, 2006.

CHILDREN'S ideas about living things. [S.l.]: Leads National Curriculum Science Support Project, 1992. Disponível em: <www.learner.org/courses/essential/life/support/

1_Livingthings.pdf >. Acesso em: 20 jan. 2010.

CUNHA, A. M. O. (1993). Educação para saúde: um estudo das explicações das crianças, adolescentes e adultos para as doenças infecciosas. 1993. 295 f. Dissertação (Mestrado em Educação) - Faculdade de Educação, Universidade de São Paulo, São Paulo, 1993.

CUNHA, M. C. C.; JUSTI, R. S. Analogias sobre nutrição e digestão elaboradas por crianças do ensino fundamental. In: ENCONTRO NACIONAL DE PESQUISA EM EDUCAÇÃO EM CIÊNCIAS, 6., 2007, Florianópolis. Anais... Florianópolis: FAE; Belo Horizonte: UFMG, 2008. 1 CD ROM.

DRIVER, R. Children's ideas in science. Milton Keynes: Open University Press, 1985.

DRIVER, R. Students' conceptions and the learning of science. International Journal of Science Education, London, v. 11, n. 5, p. 481-490, 1989.

HAYASHI, A. M.; PORFIRIO, N. L. S.; FAVETTA, L. R. A. A importância da experimentação na construção do conhecimento científico nas séries iniciais do ensino fundamental. In: SIMPÓSIO DE ENSINO DE GRADUAÇÃO, 4., 2006, Piracicaba. Anais... Piracicaba: Unimep, 2006. p. 1-4. Disponível em: < http://www.unimep.br/phpg/ mostraacademica/anais/4mostra/pdfs/300.pdf>. Acesso em: 17 jul. 2011.

HALLOUN, I. A.; HESTENES, D. The initial knowledge state of college physics students. The American Journal of Physics, New York, v. 53, n. 11, p. 1043-1055, 1985 a.

HALLOUN, I. A.; HESTENES, D. Common sense concepts about motion. The American Journal of Physics, New York, v. 53, n. 11, p. 1056-1065, 1985b.

KAWASAKI, C. S. Nutrição vegetal: campo de estudo para o ensino de ciências. 1998. 313 f. Tese (Doutorado em Educação) - Faculdade de Educação, Universidade de São Paulo, São Paulo, 1998. 
Os conhecimentos alternativos e científicos ...

KAWASAKI, C. S.; BIZZO, N. M. V. Fotossíntese, um tema para o ensino de ciências? Química Nova na Escola, São Paulo, n. 12, p. 24-29, nov. 2000.

KERR, K.; BEGGS, J.; MURPHY, C. Comparing children's and student teachers' ideas about science concepts. Irish Educational Studies, Abingdon, v. 25, n. 3, p. 289-302, 2006.

KWEN, B. H.. Teachers' misconceptions of biological science concepts as revealed in science examination papers. In: INTERNATIONAL EDUCATION RESEARCH CONFERENCE, 2005, Sydney. Proceedings... Melbourne: AARE, 2005.

LAWSON, A. E. The acquisition of biological knowledge during childhood: cognitive conflict or tabula rasa? Journal of Research in Science Teaching, Hoboken, v. 25, n. 3, p. 185-199, 1988.

LAWSON, A. E. The reality of general cognitive operations. Science Education, Hoboken, v. 66, n. 2, p. 229-241, 1982.

POPOV, O. Testes diagnósticos, exames e pré-conceitos dos alunos de escola primária na área das ciências naturais. Inhamissa: Instituto Nacional de Desenvolvimento da Educação, 1995. [Palestra].

SFORNI, M. S. F.; GALUCH, M. T. B. Aprendizagem conceitual nas séries iniciais do ensino fundamental. Educar em Revista, Curitiba, n. 28, p. 217-229, 2006.

SIGURJÓNSDÓTTIR, H.; THORVALDSDÓTTIR, H. L. How well do pupils understand photosynthesis?: a study in three small rural schools in Iceland. Disponível em: <http://mennta.hi.is/malthing_radstefnur/symposium9/synopsis/ nfsun9_submission_111.doc $>$. Acesso em: 15 abr. 2010.

SIMPSON, M.; ARNOLD, B. The inappropriate use of subsumers in biology learning. European Journal of Science Education, Abingdon, v. 4, n. 2, p. 173-182, 1982a.

SIMPSON, M.; ARNOLD, B. Availability of prerequisite concepts for learning biology at certificate level. Journal of Biological Education, London, v. 16, n. 1, p. 65-72, 1982b.

STAVY, R.; WAX, N. Children's conceptions of plants as living things. Human Development, Basel, v. 32, n. 2, p. 88-94, 1989.

TANNER, K.; ALLEN, D. Approaches to biology teaching and learning: understanding the wrong answers - teaching toward conceptual change. Cell Biology Education, Bethesda, v. 4, n. 2, p.112-117, 2005.

TEIXEIRA, F. M. What happens to the food we eat? Children's conceptions of the structure and function of the digestive system. International Journal of Science Education, London, v. 22, n. 5, p. 507-520, 2000.

TEIXEIRA, P. M. M. Pesquisa em ensino de biologia no Brasil (1972-2004): um estudo baseado em dissertações e teses. 2009. 406 f. Tese (Doutorado em Educação) - Faculdade de Educação, Universidade Estadual de Campinas, Campinas, 2009. Disponível em: < http:/ /libdigi.unicamp.br/document/?code=000449571 >. Acesso em: 15 abr. 2010. 
Castro, D. R.; Bejarano, N. R. R.

WOOD-ROBINSON, C. Young people's ideas about plants. Studies in Science

Education, New York, v. 19, n. 1, p. 119-135, 1991.

ZOMPERO, A. F. Concepções de alunos do ensino fundamental sobre microorganismos em aspectos que envolvem saúde: implicações para o ensino aprendizagem. Experiências em Ensino de Ciências, Cuiabá, v. 4, n. 3, p. 31-42, 2009.

Artigo recebido em 12/05/12. Aceito em 28/08/12.

Ciência E̊E Educação, v. 19, n. 1, p. 1-14, 2013 